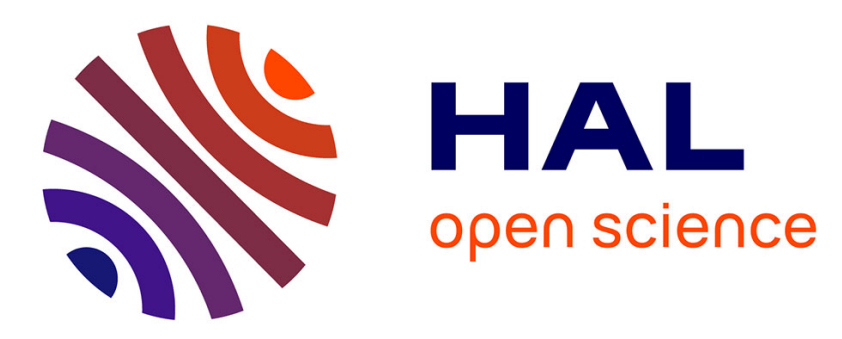

\title{
Improving Process Management in a Water Treatment Plant Using Control Modelling
}

\author{
Cleber Gustavo Dias, Fábio Santos, André Librantz, Cristiano Sousa, Luiz
}

Silva

\section{- To cite this version:}

Cleber Gustavo Dias, Fábio Santos, André Librantz, Cristiano Sousa, Luiz Silva. Improving Process Management in a Water Treatment Plant Using Control Modelling. IFIP International Conference on Advances in Production Management Systems (APMS), Sep 2016, Iguassu Falls, Brazil. pp.138-145, 10.1007/978-3-319-51133-7_17. hal-01615700

\author{
HAL Id: hal-01615700 \\ https://hal.inria.fr/hal-01615700
}

Submitted on 12 Oct 2017

HAL is a multi-disciplinary open access archive for the deposit and dissemination of scientific research documents, whether they are published or not. The documents may come from teaching and research institutions in France or abroad, or from public or private research centers.
L'archive ouverte pluridisciplinaire HAL, est destinée au dépôt et à la diffusion de documents scientifiques de niveau recherche, publiés ou non, émanant des établissements d'enseignement et de recherche français ou étrangers, des laboratoires publics ou privés.

\section{(c)(1)}

Distributed under a Creative Commons Attribution| 4.0 International License 


\title{
Improving Process Management in a Water Treatment Plant Using Control Modelling
}

\author{
Cleber Gustavo Dias ${ }^{1}$ and Fábio Cosme Rodrigues dos Santos ${ }^{1,2}$, André Felipe \\ Henriques Librantz ${ }^{1}$, Cristiano Morais de Sousa ${ }^{1}$, and Luiz Carlos da Silva ${ }^{1}$ \\ 1 Nove de Julho University, São Paulo, Brazil \\ 2 Companhia de Saneamento Básico do Estado de São Paulo, São Paulo, Brazil \\ diascg@uni9.pro.br
}

\begin{abstract}
This work presents a modelling and a simulation of a $\mathrm{pH}$ control for process management in a drinking water treatment plant. A range of historical data, or knowledge base, was used to define the behavior of each input and disturbances of the process, using the MATLAB/Simulink software. The present $\mathrm{pH}$ control modelling has been simulated and compared to some experimental tests, thus con-tributing to achieve and identify operational scenarios in a real water treatment plant. Therefore, the present results allows to predict not only the present scenari-os but also new operational conditions, in order to estimate the better process parameters and reduce some costs related to raw materials, such as the lime con-sumption, in water treatment plants.
\end{abstract}

Keywords: pH Control · Water Treatment Plant · Modelling and Simulation · Industrial Process Management

\section{Introduction}

The $\mathrm{pH}$ neutralization process, or the control of $\mathrm{pH}$, is a crucial task in wide industrial applications, such as chemical, biotechnological engineering, wastewater and water treatment plants (WTP). The $\mathrm{pH}$, as a definition, is the logarithmic value of hydrogen ion activity in an aqueous solution or a measure of the acidity or alkalinity of a solution [1]. In terms of numerical values, a solution with a $\mathrm{pH}$ equal to 7 is neutral and for an alkalinity solution, this value is greater than 7 . In an acidic solution, the $\mathrm{pH}$ value is less than 7 .

The control of a $\mathrm{pH}$ neutralization is one of the major problem in water treatment plants, particularly due to its highly nonlinear characteristics [2]. In the last years, many researchers have studied $\mathrm{pH}$ control strategies and methods to resolve or min-imize this strong nonlinearity [2].

In some cases, an extended Kalman filter (EKF) and an unscented Kalman filter (UKF) were used to estimate some values in a nonlinear $\mathrm{pH}$ process $[3,4]$. In [5], double-control scheme for $\mathrm{pH}$ process was employed to obtain a good load rejection performance, particularly simultaneous change occurs in set point and in disturbance inputs. This solution was proposed to overcome some drawbacks 
usually found in conventional PID (proportional-integral-derivative) systems, such as the robustness of the control.

In [6], a Wiener-Laguerre model was used to evaluate the $\mathrm{pH}$ neutralization process as a nonlinear model predictive control framework, based on the sequential quadratic programming algorithm. This solution was designed considering an operation of the $\mathrm{pH}$ process in distinct set points. A Wiener model identification and predictive control also was applied of a $\mathrm{pH}$ neutralization process in [7], but in this case in an effluent solution control.

A multi-model nonlinear predictive control scheme was applied in [8] to describe and handle the nonlinearities of a $\mathrm{pH}$ industry process. This approach included a parallel integral action in the controller to compensate unmeasured states.

In a WTP, for example, natural dissolved organic matter (DOM) is present and this kind of product may cause relevant problems for process control [9]. In this situation, a coagulation step should be applied to maximize the removal of DOM in water, but accordingly to [9], some coagulants are able to modify the final $\mathrm{pH}$, especially after enhanced coagulation. In [10], a reset/hybrid control application was applied an in-line $\mathrm{pH}$ process, in order to test the performance of a reset controller for a non-linear system with disturbances.

In some cases, a $\mathrm{pH}$ process requires an online monitoring and control system due to its highly nonlinear aspects [11,12]. Other researches took into account the use of artificial intelligence techniques to improve $\mathrm{pH}$ control, in particular for predictive purposes and adaptive and/or optimization strategy $[13,14,15,16,17,18,19,20,21]$.

As aforementioned, the $\mathrm{pH}$ control is a major issue in some industrial processes due to its nonlinear behavior, thus, in this context, the aim of this work consists in the modelling and simulating a $\mathrm{pH}$ closed-loop control of a real WTP, in order to better manage the process and reduce some costs related to the use of raw materials in a water treatment plant, for some operational scenarios, as well as identify the better parameters for this type of process.

\section{Methodology}

The present work has been applied for simulation purposes and some process variables were chosen by mathematical modelling. These variables were identified con-sidering their impact for $\mathrm{pH}$ control in a real drinking water treatment plant, located at São Paulo city, Brazil. The rated flow of this WTP is $33 \mathrm{~m}^{3} / \mathrm{s}$. In this context, this research has been performed in six steps, as follows:

1. Identify the process variables according to the desired $\mathrm{pH}$ behavior. Thus, consid-ering the knowledge of the operators, some parameters were identified as relevant for $\mathrm{pH}$ control, such as, chlorine dosage and fluorine dosage at the end of the pro-cess treatment, raw water flow, treated water turbidity and the lime dosage;

2. Select a range of historical data stored in a Supervisory Control and Data Acquisi-tion (SCADA system). This system is running at the local water 
plant and Figure 1 shows a screen of the SCADA used for operating the WTP and lime dosage to con-trol the $\mathrm{pH}$ of the drinking water. On this screen is possible to adjust the reference value for automatic controller or the lime pump frequency, as well as other parameters such as the lime flow, lime dosage and dosage pumps.



Fig. 1. A process screen in the SCADA system for $\mathrm{pH}$ monitoring and lime dosage

3. Identify a sample data wherein the $\mathrm{pH}$ process was being controlled in automatic mode. Table 1 shows a brief sample of the experimental data used for modelling and simulation.

Table 1. Some historical data selected from SCADA software

\begin{tabular}{cccccc}
\hline Data and Time & \multicolumn{2}{c}{ Measured Turbidity } & $\begin{array}{c}\text { Chlorine } \\
\text { dosage }\end{array}$ & $\begin{array}{c}\text { Fluorine } \\
\text { dosage } \\
\text { (mH }\end{array}$ & $\begin{array}{c}\text { Raw water } \\
\text { flow } \\
\text { ( } \mathbf{m 3} / \mathbf{s})\end{array}$ \\
\hline 2015-10-06 03:39:08:117 & 7.93 & 0.42 & 1.74 & 0.64 & 13.82 \\
2015-10-06 03:41:38:163 & 9.04 & 0.45 & 1.64 & 0.61 & 13.85 \\
2015-10-06 03:44:08:147 & 8.96 & 0.46 & 1.66 & 0.63 & 13.86 \\
2015-10-06 03:46:38:677 & 9.04 & 0.45 & 1.68 & 0.68 & 13.87 \\
2015-10-06 03:49:08:177 & 8.70 & 0.45 & 1.67 & 0.73 & 13.86 \\
2015-10-06 03:51:38:193 & 8.33 & 0.44 & 1.66 & 0.80 & 13.77 \\
2015-10-06 03:54:08:803 & 8.34 & 0.45 & 1.69 & 0.60 & 13.81 \\
\hline
\end{tabular}

4. Load these data in the MATLAB $\AA$ software and execute some specific commands to determine the behavior (transfer function) of each input and respective output variable. In this case, the output variable is the measured $\mathrm{pH}$. The following com-mands were used:

- Command "iddata": create a data object to encapsulate the input/output data and their properties(Eq. 1).

$$
D A T=i \operatorname{ddata}(Y, U, T s)
$$


Where: $\mathrm{Y}=$ output, $\mathrm{U}=$ input and $\mathrm{Ts}=$ sampling interval

- Command "tfest": This MATLAB (c) function estimates a continuoustime transfer function, sys, using time- or frequency-domain data, DAT obtained from "iddata" command, and contains np poles, as follows Eq 2 :

$$
\text { sys }=t f e s t(D A T, n p)
$$

5. Modelling each input/output variable and/or equipment in the MATLAB Simulink environment, in order to proceed to the operational scenarios simulation. Figure 2 shows an aerial view of the WTP used for modelling and experimental validation. Figure 3 shows a final model of each variable, i.e., chlorine dosage, treated turbidity and flow, as well as the equipment behavior, such as lime and fluorine pumps, after modelling step. Figure 3 also highlights a transfer function obtained for one disturb-ance, i.e., for chlorine dosage, using Equations 1 and 2. This function is a relation between the chlorine dosage and its influence in the $\mathrm{pH}$ value. Equations 1 and 2 also were used for determining the other disturbances, such as fluorine dosage, flow and turbidity influence.

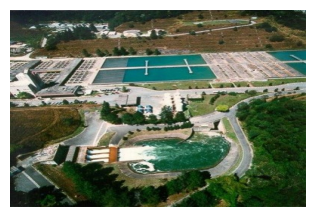

Fig. 2. The water treatment plant used for modelling and simulation



Fig. 3. The process modelling in the MATLAB/Simulink (C) software

6. The performance of the final model is measured by the mean absolute error (MAE), as shown in Equation 3:

$$
M A E=\frac{1}{N} \sum_{i=1}^{N} t_{i}-y_{i}
$$


Where, is desired value; is value obtained from the mathematical model and $\mathrm{N}$ is number of existing samples. The next section shows the results and discussion about the simulation of three operational scenarios using the model depicted in Figure 3.

\section{Results and Discussion}

This session shows the results and discussion about the simulation of three operational scenarios using the final mathematical model depicted in Figure 33. In each case, the initial conditions were used to start the simulation and proceed with experi-mental validation.

- First scenario (initial conditions): in this case the initial parameters were defined as follows: chlorine dosage $=1.74 \mathrm{mg} / \mathrm{l}$, fluorine dosage $=0.645$ $\mathrm{mg} / \mathrm{l}$, raw water flow $=13.83 \mathrm{~m}^{3} / \mathrm{s}$ and treated turbidity $=0.422$ NTU. Figure 3 (a) and (b) show the lime pumps dosage, and the $\mathrm{pH}$ obtained in the experimental and simulated data.

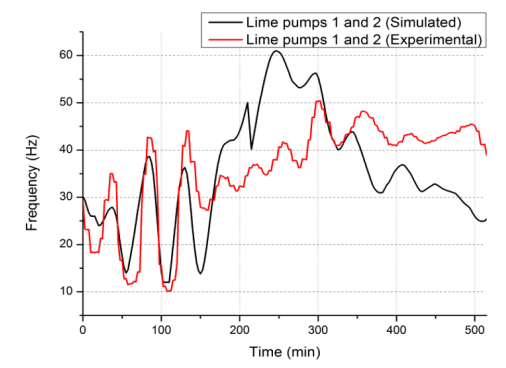

(a) Frequency of lime pumps 1 and 2

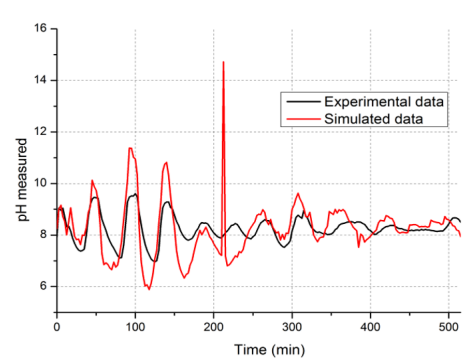

(b) $\mathrm{pH}$ measured for experimental and simulated data

Fig. 4. a) Frequency of lime pumps 1 and 2 and b) pH measured for experimental and simulated data

- Second scenario (initial conditions): in this case the initial conditions were defined as follows: chlorine dosage $=1.86 \mathrm{mg} / \mathrm{L}$, fluorine dosage $=0.654$ $\mathrm{mg} / \mathrm{L}$, raw water flow $=17.24 \mathrm{~m} 3 / \mathrm{s}$ and turbidity $=0.33$ NTU. Figures 3 (a) and (b) show the lime pumps dosage and the $\mathrm{pH}$ obtained in the experimental and simulated data.

- Third scenario (initial conditions): in this case the initial conditions were defined as follows: chlorine dosage $=1.76 \mathrm{mg} / \mathrm{L}$, fluorine dosage $=0.691$ $\mathrm{mg} / \mathrm{L}$, raw water flow $=27.03 \mathrm{~m}^{3} / \mathrm{s}$ and turbidity $=0.272$ NTU. Figures $6 \mathrm{a}$ and $6 \mathrm{~b}$ show the lime pumps dosage and the $\mathrm{pH}$ obtained in the experimental and simulated data. 


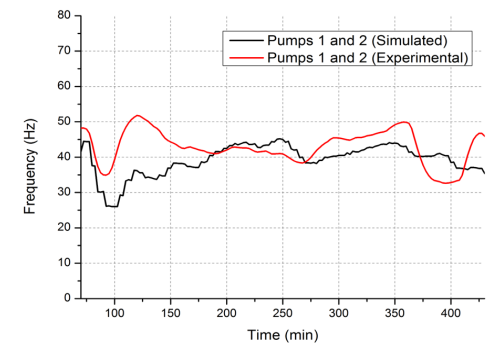

(a) Frequency of lime pumps 1 and 2

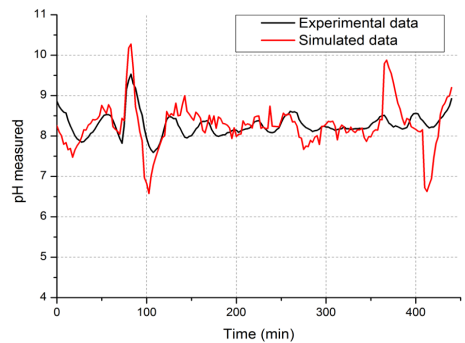

(b) $\mathrm{pH}$ measured for experimental and simulated data

Fig. 5. a) Frequency of lime pumps 1 and 2 and b) pH measured for experimental and simulated data

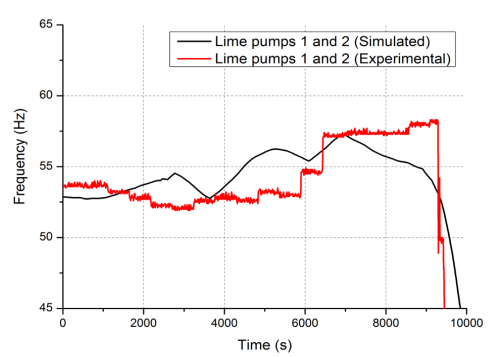

(a) Frequency of lime pumps 1 and 2

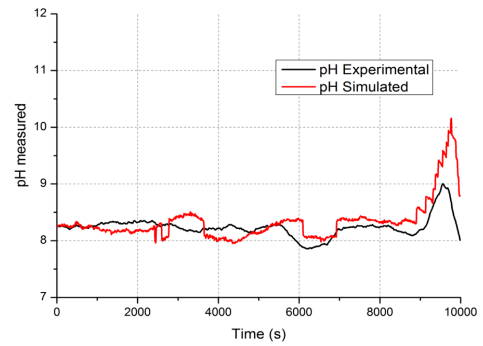

(b) $\mathrm{pH}$ measured for experimental and simulated data

Fig. 6. a) Frequency of lime pumps 1 and 2 and b) pH measured for experimental and simulated data

The results show a good approximation between the simulated and experimental data, even though some operational points should be better evaluated in each case. On the other hand, it should be noted that the results achieved in the scenario 3 are better than those obtained in other cases, as this last scenario have considered a data sampled time equal to 10 seconds from the knowledge base (SCADA system), while in the first and second cases were employed data sample time equal to 2.5 minutes. Table 2 shows the MAE values for each scenario.

The frequency of each lime pump is a relevant parameter capable of estimating the lime consumption in the WTP, since this parameter is useful to determine lime flow. Today, the $\mathrm{pH}$ control at the water plant used for experimental validation requires more than 15 tons of lime per day, when the raw water flow is near $33 \mathrm{~m}^{3} / \mathrm{s}$. 
Table 2. Values of MAEs scenarios

\begin{tabular}{ccc}
\hline Scenario & $\begin{array}{c}\text { Mean Absolute } \\
\text { Error (MAE) of the frequency of lime pumps Error }\end{array}$ & $\begin{array}{c}\text { Mean Absolute } \\
\text { (MAE) of the pH value }\end{array}$ \\
\hline 1 & $9.28 \mathrm{~Hz}$ & 0.573 \\
2 & $5.69 \mathrm{~Hz}$ & 0.334 \\
3 & $2.06 \mathrm{~Hz}$ & 0.192 \\
\hline
\end{tabular}

\section{Conclusions}

This work presented a model of a $\mathrm{pH}$ control for process management in a drinking water treatment plant. A data set obtained from a SCADA software was used to define the behavior of each input and disturbances of the process, using the MATLAB/Simulink (C) software. The results of the three operational scenarios show a good approximation between simulated and experimental data, thus, the present model can be used in other operational conditions, in order to estimate the lime pump frequency and the $\mathrm{pH}$ in the treated water, as well as improve the raw water quality and reduce the lime consumption. The current mathematical model can be a useful tool for a decision-making process and production management; particularly for estimating the daily chemical refills in the WTP, which is not an easy task. It should be mentioned that lime consumption could represent $15 \%$ of total operational costs in a WTP [22]. Moreover, the lime consumption could be better evaluated due to initial parameters of the WTP. Further investigations should be considered, using an artificial intelligence approach, to estimate the minimum dosage of the lime pumps, maintaining the quality of the treated water. That could lead to cost reduction in the water treatment process.

\section{References}

1. Hermansson, A.W.and Syafiie, S.: Model Predictive Control of pH Neutralization Processes: A Review. Control Engineering Practice pp. 98-109 (2015)

2. Abdullah, N., Karsiti, M., Ibrahim, R.: A Review of pH Neutralization Process Control. In: 4th International Conference on Intelligent and Advanced Systems. vol. 2, pp. 594-598. IEEE (2012)

3. Barhoumi, A., Ladhari, T., M'sahli, F.: The Extended Kalman Filter for Nonlinear System: Application to System of Waste Water Treatment. In: 15th International Conference on Sciences and Techniques of Automatic Control and Computer Engineering. pp. 445-450. IEEE (2014)

4. Romanenko, A., Santos, L.O., Afonso, P.A.: Unscented Kalman Filtering of a Simulated pH System. Industrial \& Engineering Chemistry Research 43(23), 7531-7538 (2004)

5. Shobana, S., Panda, R.C.: Control of pH Process Using Double-control Scheme. Nonlinear Dynamics 67(3), 2267-2277 (2012)

6. Mahmoodi, S., Poshtan, J., Jahed-Motlagh, M.R., Montazeri, A.: Nonlinear Model Predictive Control of a $\mathrm{pH}$ Neutralization Process Based on Wiener-Laguerre Model. Chemical Engineering Journal 146(3), 328-337 (2009) 
7. Gomez, J., Jutan, A., Baeyens, E.: Wiener Model Identification and Predictive Control of a pH Neutralisation Process. IEE Proceedings-Control Theory and Applications 151(3), 329-338 (2004)

8. Hermansson, A.W., Syafiie, S.: Control of pH Neutralization System Using Nonlinear Model Predictive Control with I-controller. In: IEEE International Conference on Industrial Engineering and Engineering Management. pp. 853-857. IEEE (2014)

9. Xie, J., Wang, D., van Leeuwen, J., Zhao, Y., Xing, L., Chow, C.W.: pH Modeling for Maximum Dissolved Organic Matter Removal by Enhanced Coagulation. Journal of Environmental Sciences 24(2), 276-283 (2012)

10. Carrasco, J., Baños, A.: Reset Control of an Industrial In-line pH Process. IEEE Transactions on Control Systems Technology 20(4), 1100-1106 (2012)

11. Jacobs, O., Hewkin, P., While, C.: Online Computer Control of $\mathrm{pH}$ in an Industrial Process. In: IEE Proceedings D-Control Theory and Applications. vol. 127, pp. 161-168. IET (1980)

12. Aparna, V.: Development of Automated pH Monitoring \& Control System Through USB Data Acquisition. In: 6th IEEE Power India International Conference. pp. 16. IEEE (2014)

13. Tan, W., Lu, F., Loh, A., Tan, K.C.: Modeling and Control of a Pilot pH Plant Using Genetic Algorithm. Engineering Applications of Artificial Intelligence 18(4), 485-494 (2005)

14. Menzl, S., Stühler, M., Benz, R.: A Self Adaptive Computer-based pH Measurement and Fuzzy-control System. Water Research 30(4), 981-991 (1996)

15. Saji, K., Kumar, M.S.: Fuzzy Sliding Mode Control for a pH Process. In: IEEE International Conference on Communication Control and Computing Technologies. pp. 276-281. IEEE (2010)

16. Sabharwal, J., Chen, J.: Intelligent pH control Using Fuzzy Linear Invariant Clustering. In: Proceedings of the Twenty-Eighth Southeastern Symposium on System Theory. pp. 514-518. IEEE (1996)

17. Mollov, S., Babuska, R., Abonyi, J., Verbruggen, H.B.: Effective Optimization for Fuzzy Model Predictive Control. IEEE Transactions on Fuzzy Systems 12(5), 661$675(2004)$

18. Xu, C., Shin, Y.C.: A Multilevel Fuzzy Control Design for a Class of Multiinput Single-Output Systems. IEEE Transactions on Industrial Electronics 59(8), 3113$3123(2012)$

19. Loh, A., Looi, K., Fong, K.: Neural Network Modelling and Control Strategies for a pH Process. Journal of Process Control 5(6), 355-362 (1995)

20. Böling, J.M., Seborg, D.E., Hespanha, J.P.: Multi-model Adaptive Control of a Simulated pH Neutralization Process. Control Engineering Practice 15(6), 663$672(2007)$

21. Navghare, S., Bodhe, G.: Design and Implementation of Real Time Neurofuzzy Based pH Controller. In: 2009 Second International Conference on Emerging Trends in Engineering \& Technology. pp. 946-952. IEEE (2009)

22. Plappally, A.K., Lienhard, J.H.: Costs for Water Supply, Treatment, End-use and Reclamation. Desalination and Water Treatment 51(1-3), 200-232 (2013) 